\title{
ATIVIDADES PRODUTIVAS E ESTRATÉGIAS TERRITORIAIS DE SOBREVIVÊNCIA EM COMUNIDADES DE PESCADORES DO RIO PANACUERA (ABAETETUBA - PARÁ - BRASIL)
}

\author{
PRODUCTIVE ACTIVITIES AND TERRITORIAL STRATEGIES FOR \\ SURVIVAL IN FISHERMAN COMMUNITIES OF THE PANACUERA RIVER \\ (ABAETETUBA - PARÁ - BRAZIL)
}
ACTIVIDADES PRODUCTIVAS Y ESTRATEGIAS TERRITORIALES PARA LA SUPERVIVENCIA EN LAS COMUNIDADES DE PESCADORES DEL RÍO PANACUERA (ABAETETUBA - PARÁ - BRASIL)

\section{Resumo}

Este artigo visa analisar a importância econômica da atividade pesqueira na reprodução social dos pescadores de comunidades localizadas no rio Panacuera, no município de Abaetetuba, estado do Pará, Brasil. Para tanto, foram realizados levantamentos de dados primários e secundários. Os dados primários foram coletados por meio de conversas informais e da aplicação de questionários in loco a 20 pescadores das comunidades, ao longo do rio, entre 2018 e 2019, e os dados secundários resultaram de levantamentos bibliográficos, realizados em revistas científicas e em livros especializados. A partir da sistematização dos dados coletados, identificou-se a grande relevância econômica da pesca artesanal para a reprodução social dos pescadores do rio Panacuera, porém ela está atrelada a outras atividades que complementam a renda desses pescadores os quais realizam uma jornada exaustiva, cerca de 12 horas levando pouquíssimo alimento nessa jornada para obterem o mínimo de dignidade na mesa de seus familiares. Em associação com a pesca, realizam outras atividades, destacando-se o extrativismo do açaí que tem lugar especial na alimentação e na renda desses trabalhadores. Assim, embora outras atividades sejam desenvolvidas de modo complementar, a pesca continua a ser base a fundamental de alimentação e renda desses pescadores.

Palavras-chave: Pesca artesanal. Estratégias territoriais de sobrevivência. Rio Panacuera. Amazônia.

\section{Abstract}

This article aims to analyze the economic importance of fishing activity in the social reproduction of fishermen from communities located on the Panacuera River, in the municipality of Abaetetuba, state of Pará, Brazil. To this end, surveys of primary and secondary data were carried out. The primary data were collected through informal conversations and the application of questionnaires in loco to 20 fishermen from the communities, along the river, between 2018 and 2019, and the secondary data resulted from bibliographic surveys, carried out in scientific magazines and in specialized books. From the systematization of the data collected, the great economic relevance of artisanal fishing for the social reproduction of the fishermen of the Panacuera River was identified, however it is linked to other activities that complement the income of these fishermen who undertake an exhaustive journey, about 12 hours taking very little food on this journey to obtain the minimum dignity at the table of their family members. In association with fishing, they carry out other activities, notably the extraction of açai which has a special place in the food and income of these workers. Thus, although other activities are developed in a complementary manner, fishing continues to be the basic source of food and income for these fishermen.

Keywords: Artisanal fishing. Territorial survival strategies. Panacuera river. Amazon.

\section{Resumen}

Este artículo tiene como objetivo analizar la importancia económica de la actividad pesquera en la reproducción social de los pescadores de las comunidades ubicadas en el río Panacuera, en el municipio de Abaetetuba, estado de Pará, Brasil. Para ello, se realizaron encuestas de datos primarios y secundarios. Los 
datos primarios se recolectaron mediante conversaciones informales y la aplicación de cuestionarios in loco a 20 pescadores de las comunidades, a lo largo del río, entre 2018 y 2019, y los datos secundarios resultaron de encuestas bibliográficas, realizadas en revistas científicas y en libros especializados. A partir de la sistematización de los datos recolectados se identificó la gran relevancia económica de la pesca artesanal para la reproducción social de los pescadores del río Panacuera, sin embargo se vincula a otras actividades que complementan los ingresos de estos pescadores que emprenden un recorrido exhaustivo, aproximadamente 12 horas llevando muy poca comida en este recorrido para obtener la mínima dignidad en la mesa de sus familiares. En asociación con la pesca, realizan otras actividades, entre las que destaca la extracción de açaí, que tiene un lugar especial en la alimentación y los ingresos de estos trabajadores. Así, aunque otras actividades se desarrollan de forma complementaria, la pesca sigue siendo la fuente básica de alimentación e ingresos de estos pescadores.

Palabras clave: Pesca artesanal. Estrategias de supervivencia territorial. Río Panacuera Amazônia.

\section{INTRODUÇÃO}

A organização econômica e social de uma população rural expressa traços tradicionais locais e regionais e reitera a afirmativa de que as comunidades tradicionais não devem ser vistas como antiquadas ou alienadas, mas, sim, como detentoras de formas diferenciadas de organização da vida diária, diferentemente de populações que vivem em zonas urbanas (CARNEIRO, 2019). No contexto amazônico ou, mais especificamente, nas comunidades localizadas no rio Panacuera, no município de Abaetetuba, estado do Pará, Brasil, tal realidade pode ser identificada a partir dos moradores ribeirinhos, pois o acesso à energia elétrica e aos meios de comunicação se fazem presentes, contribuindo para a conservação do pescado capturado nas pescarias locais, bem como na locomoção e na comunicação destes indivíduos com o mundo.

O estado do Pará reúne um dos maiores contingentes de trabalhadores envolvidos com a pesca artesanal, cerca de 30.000 mil pescadores estão cadastrados no Estado (SAPOMEMA, 2018). Estes são responsáveis por grande parte do abastecimento do mercado interno, respondendo por mais da metade do pescado consumido internamente, conforme informações de Santos (2005), que aborda, em seu trabalho, a importância da pesca do estado do Pará, quando se trata da produção pesqueira regional e nacional.

No que se refere às comunidades do rio Panacuera, a pesca artesanal vem sendo desenvolvida na região, ao longo de décadas, por indivíduos dotados de conhecimentos, que procuram retirar das águas, dia após dia, o sustento familiar. A pesca é a principal atividade desenvolvida, com destaque para a produção de camarão, de mapará, de pescada, de dourada, entre outras espécies. Além disso, existem distintos recursos naturais, que os pescadores deste estudo utilizam, tal como a extração do açaí, a qual desempenha importante função complementar, tanto na dieta alimentar quanto na geração de renda, pois muitos pescadores, em decorrência da diminuição da captura do pescado, nos últimos anos, se desdobram numa dupla jornada de trabalho, tanto no ambiente aquático quanto no terrestre, buscando o que chamamos neste texto de estratégias territoriais de sobrevivência, conforme estudos já realizados por Silva et al. (2016), Silva et al. (2017) e Silva et al. (2018), que demonstram que tais atividades nada mais são do que fontes de subsistência diversificadas, que auxiliam os indivíduos na manutenção de seus modos de vida.

Desse modo, buscou-se analisar a importância econômica da pesca para a reprodução dos pescadores locais, bem como observar de que modo o extrativismo do açaí vem contribuindo para o sustento familiar dos 


\section{Atividades produtivas e estratégias territoriais de sobrevivência em comunidades de pescadores do Rio Panacuera (Abaetetuba - Pará - Brasil)}

pescadores do rio Panacuera, entendendo que se tratam de atividades com organizações sociais próprias, que englobam trabalhadores com relações de parentesco, de amizade e de confiança.

Portanto, este artigo vem contribuir no sentido de evidenciar a relevância econômica da produção pesqueira no rio Panacuera, bem como busca ressaltar que, embora a pesca seja a principal atividade desenvolvida no espaço observado, outras atividades são desenvolvidas, de modo complementar, destacandose o extrativismo do açaí e a comercialização de outros produtos extraídos da floresta, que são negociados no comércio local e regional, no baixo Tocantins, como frutos e animais e, ainda, pequenos (galinhas, patos) e médios animais (porcos, carneiros), criados em quintais ou próximos das residências.

\section{O RIO PANACUERA E A PESQUISA}

As comunidades do rio Panacuera, área de estudo deste artigo, se localizam entre os municípios de Abaetetuba e de Igarapé-Miri, em que o rio faz limite com esses municípios, existindo distinções de nomenclatura pelos moradores locais, sendo denominado de rio Panacuera pelos habitantes de Abaetetuba e de rio Panacauera pelos habitantes de Igarapé-Miri.

Essas denominações surgiram para diferenciar os dois lados dos municípios atravessados pelo rio, pois um dos lados do rio pertence ao município de Igarapé Miri e o outro pertence a Abaetetuba. Com isso, as pessoas que nunca estiveram no local podem chegar aonde desejam, indicando o nome da localidade a ser visitada, facilitando o trabalho do condutor da embarcação.

Como indicado, o rio Panacuera é um rio de fronteira entre os municípios de Abaetetuba e de IgarapéMiri, os quais estão localizados na região nordeste do estado do Pará e têm envolvimento direto com a pesca e com o extrativismo do açaí. Os moradores de ambos os municípios fazem a pesca artesanal em conjunto, para beneficiar seus familiares e os membros das comunidades, desenvolvendo a economia e a estrutura social locais.

O nome Panacuera é oriundo do tupi-guarani. Etimologicamente, a palavra é produto da justaposição de panaku, prefixo que significa chapéu ou cobertura, e de era, sufixo, podendo significar muito ou velho, resultando na expressão Chapéu Velho. Tais informações foram fornecidas por Santiago Quaresma Junior, professor pesquisador do município de Igarapé-Miri, em entrevista realizada em 2018.

Na Figura 1, é possível visualizar a localização do rio Panacuera ${ }^{1}$, o qual desagua no Tocantins.

\footnotetext{
${ }^{1}$ As características desse rio o classificam como "furo", por ligar dois rios diferentes. 
Figura 1 - Rio Panacuera (circulado em vermelho), entre os municípios de Abaetetuba e de Igarapé-Miri.

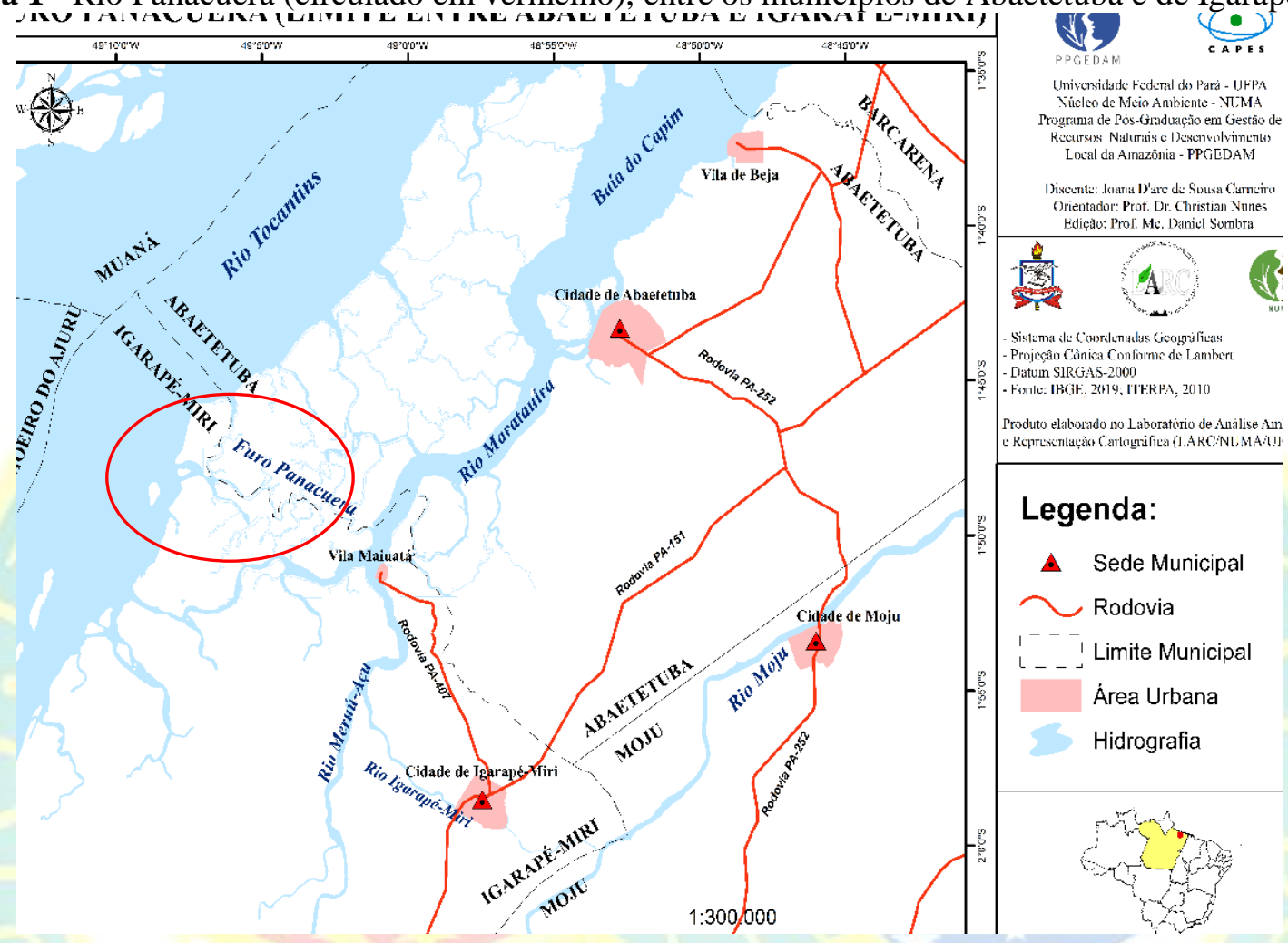

Fonte: elaborado por LARC/NUMA/UFPA, com base em IBGE (2019) e ITERPA (2010).

Diante do exposto, observa-se que existe uma relação de proximidade entre os pescadores e o rio, o lugar onde vivem, sendo seus modos de vida moldados pelas condições que lhes são apresentadas pela atividade pesqueira e pelo extrativismo. Essa proximidade possibilita o conhecimento das áreas mais propícias para as pescarias, onde podem encontrar os peixes mais comuns, para a sua alimentação e renda, bem como a identificação de áreas que oferecem algum risco para as suas vidas.

Para elucidar os resultados desta pesquisa, consideraram-se os seguintes procedimentos metodológicos: levantamento de informações primárias e secundárias, sendo que, para a obtenção de informações primárias, foram realizadas pesquisas de campo na região do rio Panacuera, entre 2018 e 2019. Inicialmente, no trabalho de campo exploratório, foram realizadas conversas informais com os pescadores, em um período que durou cerca de cinco dias, no qual foi possível identificar, ainda que de modo provisório, como se desenvolve a pesca e quais são as atividades complementares na geração de renda.

Nas pesquisas de campo posteriores, foram realizadas aplicações de questionários com um total de 20 pescadores, englobando aqueles pescadores que compõem as turmas de pesca e aqueles que, atualmente, pescam de modo individual, mas que se encontravam inseridos nessas turmas anteriormente (Figura 2). Por

\footnotetext{
${ }^{2}$ Turma de pesca é a denominação local para os grupos de pescadores, que se reúnem para a atividade pesqueira, a partir de um planejamento realizado coletivamente, por todos os membros da turma.
} 


\section{Atividades produtivas e estratégias territoriais de sobrevivência em comunidades de pescadores do Rio Panacuera (Abaetetuba - Pará - Brasil)}

meio dos questionários, os pescadores entrevistados indicaram índices qualitativos e quantitativos, que possibilitaram entender a organização e a importância da atividade pesqueira no rio Panacuera.

Figura 2 - Encontro com uma das turmas de pesca.

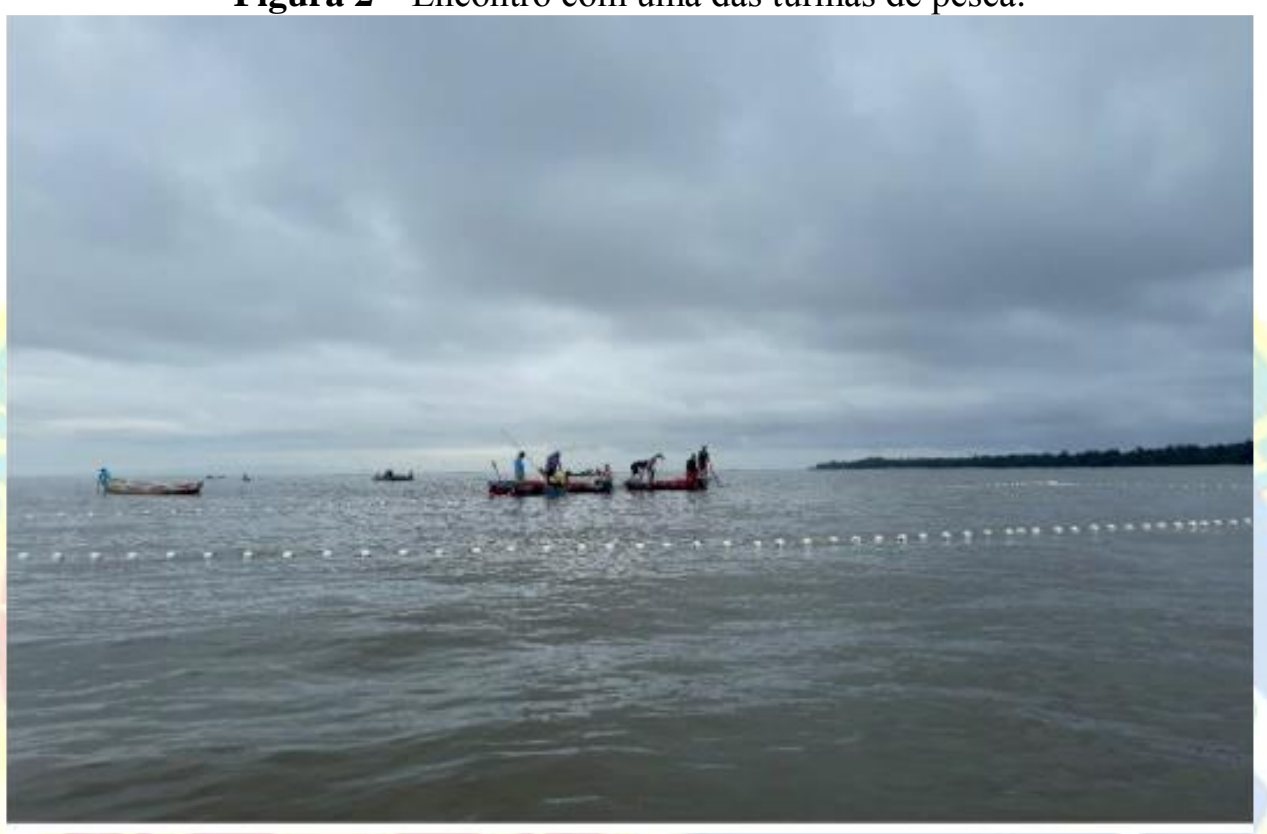

Fonte: acervo de pesquisa de campo (2019).

As informações secundárias resultaram da pesquisa bibliográfica de autores que discutem o tema, notadamente, as leituras de Ferri (1997), Diegues (1993; 2012), Gondim (2003), Silva (2006; 2012), Santos (2005), Begossi (2001; 2004; 2006), Furtado (1993), Moraes (1996; 2007), entre outros, as quais foram de grande valia e embasaram teoricamente o trabalho de campo realizado na área de estudo. Dessa forma, a partir dos dados coletados, foi possível compreender a composição de renda dos moradores e seus subsídios para a sobrevivência territorial.

\section{A PESCA ARTESANAL E OS CONHECIMENTOS QUE PERMEIAM AS PESCARIAS NO RIO} PANACUERA

A pesca artesanal na região amazônica e, especificamente, no Pará, vem se desenvolvendo, com artes de pesca simples e artesanais, ocorrendo, não raramente, com apetrechos confeccionados pelos próprios pescadores, com a utilização de materiais comprados nos centros urbanos locais ou, mesmo, extraídos da natureza (SANTOS, 2005; SILVA, 2006).

Diegues (2012, p. 165), em sua pesquisa sobre o pescador artesanal, indica que esse indivíduo sabe o momento correto de utilizar os apetrechos de pesca e conhece o seu manuseio, mostrando sabedoria acumulada não só pela experiência, mas por saber ouvir os ensinamentos dos mais velhos, difundidos nas pescarias.

O aprendizado do pescador é, geralmente, repassado de pai para filho, por meio do trabalho diário, em que os mais velhos ensinam como reconhecer, no rio, o momento mais apropriado para a captura do pescado, 


\section{Atividades produtivas e estratégias territoriais de sobrevivência em comunidades de pescadores do Rio Panacuera (Abaetetuba - Pará - Brasil)}

guiando-se pela maré e pelos ciclos da lua. Segundo Ferri (1997), o aprendizado pelo processo, em muitas situações, é sutil, de forma que os próprios aprendizes não se dão conta de que estão aprendendo e, muitas vezes, quando são questionados sobre como aprenderam tal habilidade, ouve-se a seguinte resposta: "Aprendi sozinho".

Além do aprendizado como resultado do acúmulo de experiências, o conhecimento sobre pesca ainda pode ser entendido, pelos pescadores mais experientes, como um dom dado por Deus, como se evidenciou na fala de um pescador experiente:

Quero deixar para meus filhos ou netos, o dom que Deus me deu, foi ele que me ensinou a reconhecer onde estão os cardumes de peixe e saber a quantidade e o tamanho dos cardumes. Tenho muita gratidão, porque eu trabalho como pescador há mais de 55 anos (DEPOIMENTO DO PESCADOR A, 2018).

A partir desse relato, identifica-se o conhecimento do pescador, quanto às pescarias, e, também, a sua preocupação, para com a reprodução de seus familiares e do seu meio de obtenção de renda, pois se entende que não são todos os pescadores que possuem a capacidade de identificar os cardumes de peixes no rio, pois trata-se de um saber que advém da experiência cotidiana. Conforme identificou Begossi (2004), em sua pesquisa com o uso da metodologia de coleta de informações por "marcação de pesqueiros", os pescadores mais experientes são conhecedores do espaço de pesca, acessando-o de forma otimizada, quando necessário.

Nesse contexto, destaca-se, nas pescarias no rio Panacuera, o trabalho do taleiro, designação dada ao líder do grupo de pesca, que é o pescador mais experiente e que detém as técnicas de reconhecimento das áreas, nas quais se encontram os cardumes, sendo o responsável por guiar o grupo pelas águas e por saber o momento exato de cercar e de capturar os cardumes de pescado no rio.

Conforme a pesquisa de campo, cada turma de pesca possui um taleiro, sem o qual os pescadores não saem para a pescaria, pois é ele quem direciona todos os movimentos dos pescadores, de modo sincronizado. Essa sincronia advém da prática diária, do conhecimento da arte da pesca, em que os pescadores trabalham coletivamente, com um sincronismo na hora de remar e de jogar as redes, bem como de "bater as varas" na água para não deixar o peixe escapar. Isso acontece somente quando o especialista em ouvir os cardumes mergulha, e dá o sinal de que há cardume em um determinado local, tudo tem que ser muito rápido, caso um dos pescadores erre, todo esse trabalho pode causar a perda de um bom cardume. A pesca artesanal é uma arte, uma espécie de luta entre o homem e o peixe, é uma reunião entre familiares e amigos, todos em busca de uma pescaria produtiva.

A presença de um taleiro, ainda que fundamental para o aumento das possibilidades de uma boa pescaria entre as turmas de pesca, nem sempre garante o seu sucesso, pois, nas entrevistas realizadas, os pescadores confirmam que a pesca está mais difícil a cada dia e que, algumas vezes, passam até três dias sem conseguir pescar, acumulando gastos financeiros e desgastes físicos, uma vez que os leva a realizar uma dupla jornada de trabalho, durante o período de safra do açaí. 


\section{Atividades produtivas e estratégias territoriais de sobrevivência em comunidades de pescadores do Rio Panacuera (Abaetetuba - Pará - Brasil)}

Essa dupla jornada é feita por diversos pescadores, que realizam a pesca no horário da manhã e a colheita do fruto do açaí, para a comercialização, à tarde, obtendo, assim, o complemento do sustento familiar. É importante ressaltar que a jornada diária desses trabalhadores começa de madrugada, por volta das quatro horas, quando as turmas de pesca começam a se reunir, para, em seguida, deslocarem-se para as áreas de pesca, o que geralmente ocorre às cinco horas, com retorno próximo ao meio-dia, seguindo para os açaizais no turno seguinte.

Nessa jornada exaustiva de trabalho, identificam-se as inúmeras dificuldades enfrentadas por esses pescadores, dia após dia, pois, independentemente de ser a pesca ou a extração do açaí, ambas as atividades exigem força e presteza, por parte dos trabalhadores.

Trabalhar no rio demanda habilidade e força na condução das embarcações, na captura do pescado, além da exposição ao sol, à chuva e a outros perigos existentes no rio, tal como a pirataria. Por outro lado, trabalhar na colheita do açaí também expõem esses trabalhadores a perigos, relacionados a picadas de animais peçonhentos, bem como ao cansaço de subir/descer dos açaizeiros, sob o risco de sofrer algum acidente fatal, caso o açaizeiro quebre.

Nos períodos de safra do açaí e de desova dos peixes, os pescadores buscam alternativas de complementação de renda no valor do seguro defeso, que é financiado pelo Governo Federal, e muitos pescadores fazem a extração do açaí, bem como a sua venda, e, com isso, todos ganham um valor, que se agrega na renda familiar (SILVA et al., 2016).

Assim, a pesca vem sendo desenvolvida, em consonância com o extrativismo do açaí, principalmente em função da redução da captura do pescado. Segundo os pescadores entrevistados, a pesca tem decaído, ano após ano, e a venda do pescado está sendo menos lucrativa para o pescador, pois a quantidade do produto capturado sofreu uma diminuição.

Outro problema relatado se refere à comercialização do peixe. Esta etapa é realizada logo após a pescaria, com os pescados sendo vendidos, geralmente, em quilos ou em uma caixa plástica (equivalente a 40 kg). Para fazê-lo, o atravessador organiza o barco com gelo, para armazenar o pescado levado para as sedes municipais locais, aumentando os custos de comercialização do produto, pois os peixes viajam para lugares distantes de suas comunidades, criando um custo adicional, bem mais alto, como destaca um dos entrevistados:

Temos semanas que na pesca só conseguimos o alimento para a família. A cada ano o pescado diminui e eu acredito que foi por causa de um vazamento que aconteceu em Vila do Conde (é um distrito do município de Barcarena), há 5 anos atrás, apareceram toneladas de peixes mortos de várias espécies, talvez seja por isso que hoje, estamos sentindo a falta de peixe (DEPOIMENTO DO PESCADOR B, 2018).

A partir dessa fala, verifica-se que os moradores locais relacionam a diminuição do pescado com a ocorrência de um problema ambiental: o vazamento de resíduos minerais, em um município vizinho (Barcarena), o qual tem prejudicado o meio ambiente. Tal questão pode estar atuando negativamente sobre a disponibilidade dos recursos pesqueiros e, por conseguinte, sobre a pesca artesanal desenvolvida no rio 
Panacuera. Esta situação vem deixando esses sujeitos em situação socialmente preocupante e tornando-os mais dependentes de outras atividades extrativas, bem como do seguro defeso.

Nesse contexto, faz-se importante ressaltar outro problema apontado pelos pescadores, como possível agravante na diminuição do pescado: a pesca no período da desova, ou seja, no período do defeso. Segundo os entrevistados, existem pescadores que realizam a atividade de forma não autorizada, prejudicando o ciclo das espécies e dificultando a reprodução dos recursos pesqueiros.

Nesse sentido, o Seguro Defeso torna-se um importante alicerce financeiro do trabalhador, que não pode praticar a atividade pesqueira, durante o período da piracema. $\mathrm{O}$ valor desse seguro é primordial, para o sustento de seus familiares, contudo, mesmo recebendo o valor do seguro, o trabalhador ainda necessita de complementações de outras atividades, pois as famílias desses pescadores são, em sua maioria, numerosas, acarretando despesas altas, e, com isso, maior necessidade de recursos econômicos, para a reprodução social.

Conforme um dos entrevistados, quando a pesca está muito difícil, com poucos cardumes capturados, e quando a safra do açaí também diminui, os pescadores retornam, no final da tarde, para uma nova tentativa de captura do pescado, aumentando ainda mais a jornada de trabalho, em busca da subsistência de seus familiares. Nessas idas e vindas, sem conseguir o pescado para o sustento familiar, alguns grupos de pescadores se unem a outras turmas de pesca artesanal, deslocando-se para lugares mais distantes, como o rio Tocantins.

Nesse contexto, percebe-se a união de diferentes grupos de pescadores, em busca de sua subsistência. Segundo Diegues (1993), as turmas de pesca artesanal exemplificam a ampla diversidade cultural das comunidades de pescadores, as quais apresentam diferentes religiões e costumes.

Todavia, ainda que existam diferenças em relação a religião dos pescadores que compõem as comunidades do rio Panacuera, tais pessoas possuem em comum a preocupação, quanto ao desenvolvimento da atividade, pois, dentro das comunidades visitadas, o percentual de famílias que sobrevivem da pesca é muito alto, chegando a cerca de $90 \%$, segundo dados da pesquisa de campo. Portanto, é compreensível, por parte dos que estão nesse ramo de trabalho, a necessidade de fazer um alerta aos mais novos, quanto às dificuldades de sobreviver apenas da pesca, de ser pescador.

\section{ATIVIDADES PRODUTIVAS E ESTRATÉGIAS TERRITORIAIS DE SOBREVIVÊNCIA NO RIO PANACUERA}

Nas comunidades do rio Panacuera, existem algumas modalidades de pesca artesanal, que são mais utilizadas, pelos pescadores da região. Entre elas, destacam-se a pesca de espinhel, de rede e de curral, além da pesca do camarão.

Cada modalidade de pesca artesanal requer apetrechos específicos, para a sua realização. Os pescadores de camarão, por exemplo, utilizam matapi e iscas; os que pescam filhote e dourada utilizam espinhel; e os que pescam mapará, pescada, tainha e branquinha utilizam malhadeira. A seguir, descreve-se cada uma delas. 


\section{Atividades produtivas e estratégias territoriais de sobrevivência em comunidades de pescadores do Rio Panacuera (Abaetetuba - Pará - Brasil)}

Na pesca de espinhel (Figura 3), os pescadores utilizam uma linha, normalmente, de nylon, com uma série de anzóis, dispostos ao longo de sua extensão. As boias possibilitam ao espinhel permanecer sobre a linha d'água e, simultaneamente, ajudam os pescadores a localizar o lugar, onde o espinhel foi deixado, facilitando a atividade do pescador, ao recolher seu material de trabalho. Muitos pescadores realizam esse tipo de pesca de modo individual, devido à simplicidade de manuseio do apetrecho.

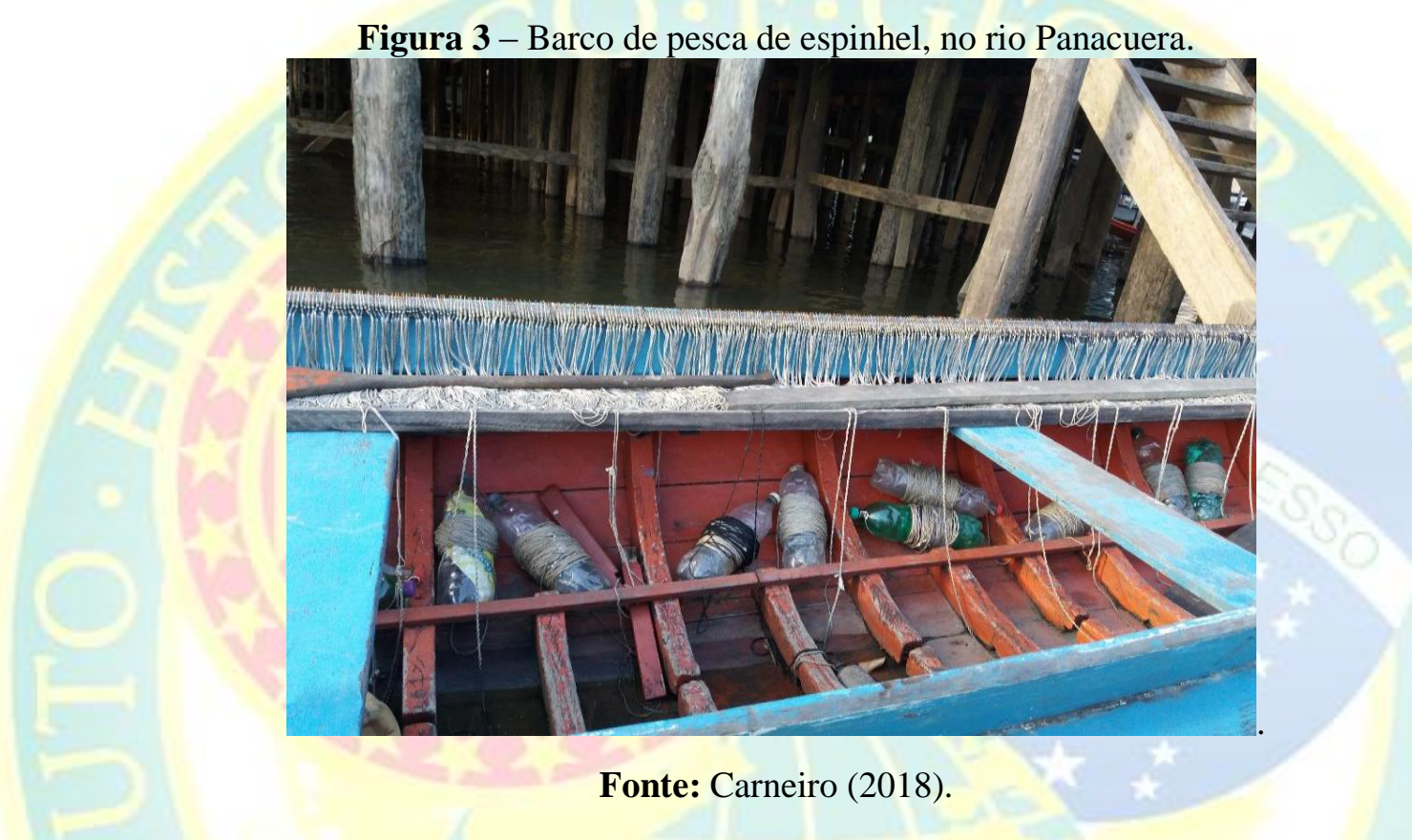

A pesca de espinhel é uma prática muito comum no rio Panacuera, sendo exercida por pescadores que buscam capturar peixes de grande porte, como a dourada, o filhote, a piaba e a piramutaba, muito comuns nas pescarias desenvolvidas pelos pescadores locais.

Os currais são estruturados com peças de madeira - como cercas, ligadas por cipós e fixadas em áreas próximas às margens, permitindo o aprisionamento das espécies, as quais ficam quase imperceptíveis, imersas nas encostas do rio. Segundo os pescadores das localidades do rio Panacuera, esses apetrechos são colocados em lugares que têm aturiá ${ }^{3}$, uma espécie de planta nativa local, em que os peixes costumam se aglomerar ou, até mesmo, fazer a desova.

Segundo alguns pescadores, esse tipo de pesca era mais usual, há alguns anos. Porém, como, aparentemente, não se tem tanto êxito neste tipo de pescaria (talvez, pela escassez do pescado, relatada, nos dias de hoje), esta vem sendo abandonada, por tipos de pesca considerados mais rentáveis.

No período do defeso, é comum os pescadores colocarem as redes de pesca na frente de suas residências, em busca de alimento para os familiares. Nessa prática, as redes ficam imersas na água, amarradas junto às árvores, pois os cardumes costumam ficar nos rios e em afluentes menores - igarapés.

\footnotetext{
${ }^{3}$ Aturiá: tipo de árvore leguminosa-papilionácea (Drepanocarpus lunatus), frondosa, que se caracteriza como um arbusto, nas margens dos rios, nas quais, segundo relatos da pesquisa de campo, os cardumes se concentram. 


\section{Atividades produtivas e estratégias territoriais de sobrevivência em comunidades de pescadores do Rio Panacuera (Abaetetuba - Pará - Brasil)}

Além dos tipos citados, outro tipo de extração desenvolvida no rio Panacuera é a captura do camarão, constituindo um importante meio de complemento da renda familiar.

No espaço do Panacuera, a pesca do camarão merece destaque, por ser uma pesca praticada, quase sempre, por pessoas do sexo feminino. Segundo a pesquisa de campo, ela é exercida por aproximadamente $80 \%$ das mulheres das comunidades do rio, as quais têm participação direta nas atividades de subsistência da família, como se depreende do relato de uma dessas pescadoras:

Todas as marés de camarão eu coloco meus matapi, mas a quantidade de matapi que eu coloco não quer dizer que vou pegar uma quantidade de camarão, faço isso para ajudar minha família, pois todos em casa gostam muito, e com isso eu ajudo na alimentação, a pesca do camarão está "rala", para conseguir 3 quilos de camarão, precisa colocar 20 matapi, há alguns anos com a mesma quantidade de matapi, conseguia o dobro dessa quantidade (depoimento da pescadora C, 2018).

Existe uma preocupação, por parte das(os) pescadoras(es), para com a pesca do camarão (Figura 4), pois muitas famílias dependem desse alimento, para ajudar na renda das famílias. Algumas vezes, o investimento não é compensador, mas o que vale, para o pescador, é a esperança de que o dia pode ser bom para a pescaria. Os instrumentos utilizados para a pesca do camarão no rio Panacuera são: matapi, farelo de trigo ou babaçu.

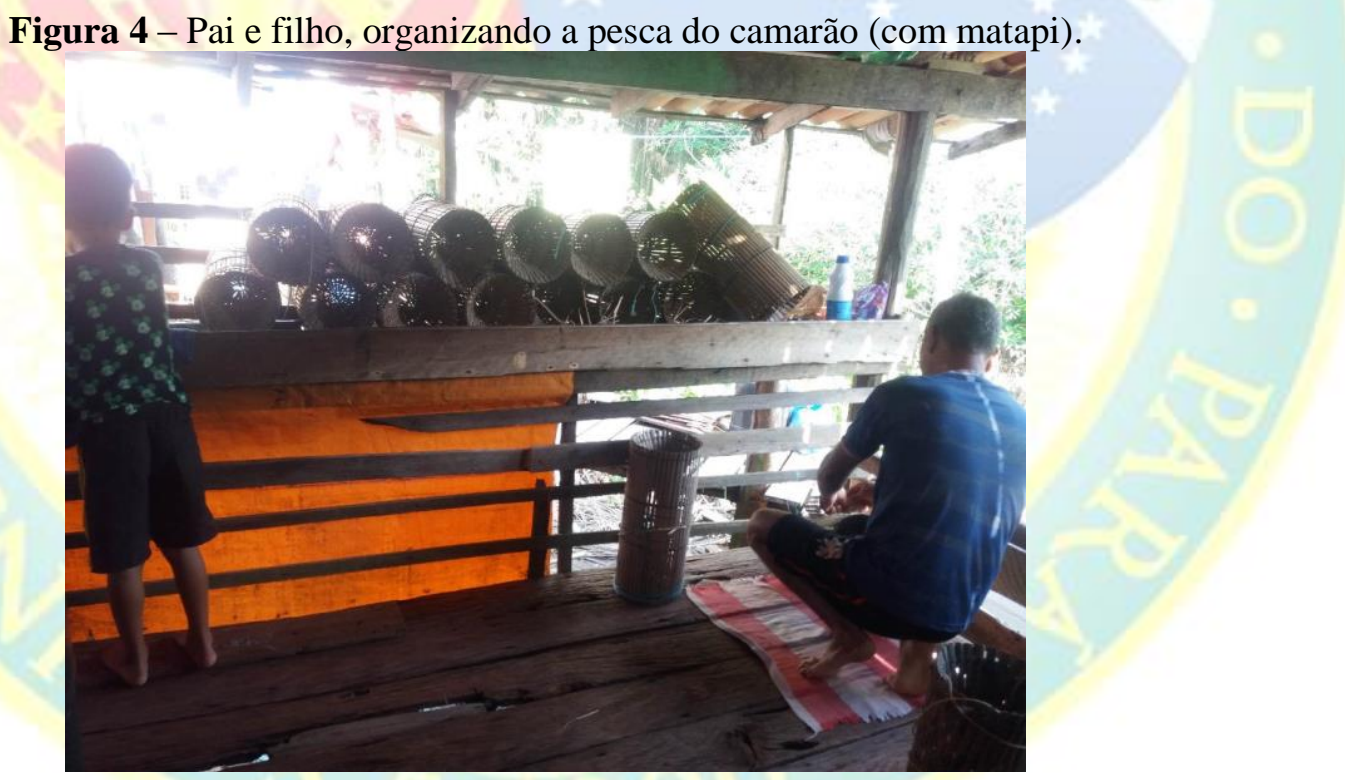

Fonte: Carneiro (2018).

Desse modo, a pesca do camarão ocorre em família, em que as crianças iniciam como ajudantes da mãe, do pai, dos avôs e dos tios, aprendendo, desde cedo, a fazer as puquequas (iscas), para colocar no matapi. Compreende-se, daí, que, no rio estudado, existem questões familiares envolvidas na pesca do camarão, tanto para a alimentação quanto para a sua comercialização, que ocorre nas próprias comunidades ou em municípios próximos da região. 


\section{Atividades produtivas e estratégias territoriais de sobrevivência em comunidades de pescadores do Rio Panacuera (Abaetetuba - Pará - Brasil)}

As crianças iniciam a aprendizagem da pesca do camarão com os pais, com os avôs ou com os tios, pois as famílias acreditam que esta é uma forma de inserir a criança ou o adolescente em uma atividade; não, como uma obrigação, para complementação da renda familiar, mas como um aprendizado para a vida adulta. Tal aprendizagem não interfere na vida escolar, pois a pesca acontece em horários diferentes dos da escola.

Portanto, a pesca do camarão é uma atividade que traz para as famílias uma renda importante, fazendose uma atividade econômica familiar local e auxiliando para que não falte o alimento nas residências. Dentre os entrevistados nesta pesquisa, somente $40 \%$ faz a venda para aumentar a renda, ou seja, grande parte das famílias realiza a pesca do camarão como fonte de alimento. Assim, a pesca do camarão constitui uma atividade essencial, que contribui diretamente para a reprodução social dos pescadores artesanais do rio Panacuera, tanto por meio da renda advinda da comercialização do produto capturado quanto por meio da alimentação.

No espaço do Panacuera, a pesca artesanal do mapará é uma das mais realizadas, pelos pescadores locais, em função de a espécie apresentar, por um lado, grandes cardumes, e, por outro, em função de ser amplamente apreciado, pelas populações locais e regionais. Para a realização da pesca do mapará, os pescadores utilizam a malhadeira, deslocando-se em pequenas embarcações, movidas a óleo diesel, tendo, além dos gastos com combustível, a alimentação, as linhas de nylon e os custos da compra e/ou da manutenção das redes de pesca.

Na pesquisa de campo, obtiveram-se dados que possibilitam mostrar as despesas das turmas de pesca, durante a atividade pesqueira. Visando tornar mais precisos os valores gastos, as despesas dos pescadores foram colocadas de modo individual (Gráfico 1), ainda que as pescarias ocorram em grupos ou em turmas de pesca. É importante ressaltar que os donos das redes de pesca têm ganhos superiores aos dos demais pescadores, uma vez que absorvem os gastos da manutenção dos materiais. Contudo, ainda que exista essa diferença, todos contribuem com valores semelhantes, relativamente às despesas de deslocamento e de alimentação.

Este gráfico se baseou em valores aproximados, fornecidos pelos pescadores, os quais não têm o costume de guardar registros financeiros, ou seja, estes dados estão registrados, somente, na memória dos pescadores, e abrangem valores compreendidos entre os meses de março e de outubro. 


\section{Atividades produtivas e estratégias territoriais de sobrevivência em comunidades de pescadores do Rio Panacuera (Abaetetuba - Pará - Brasil)}

Gráfico 1 - Balanço individual mensal de cada pescador artesanal.

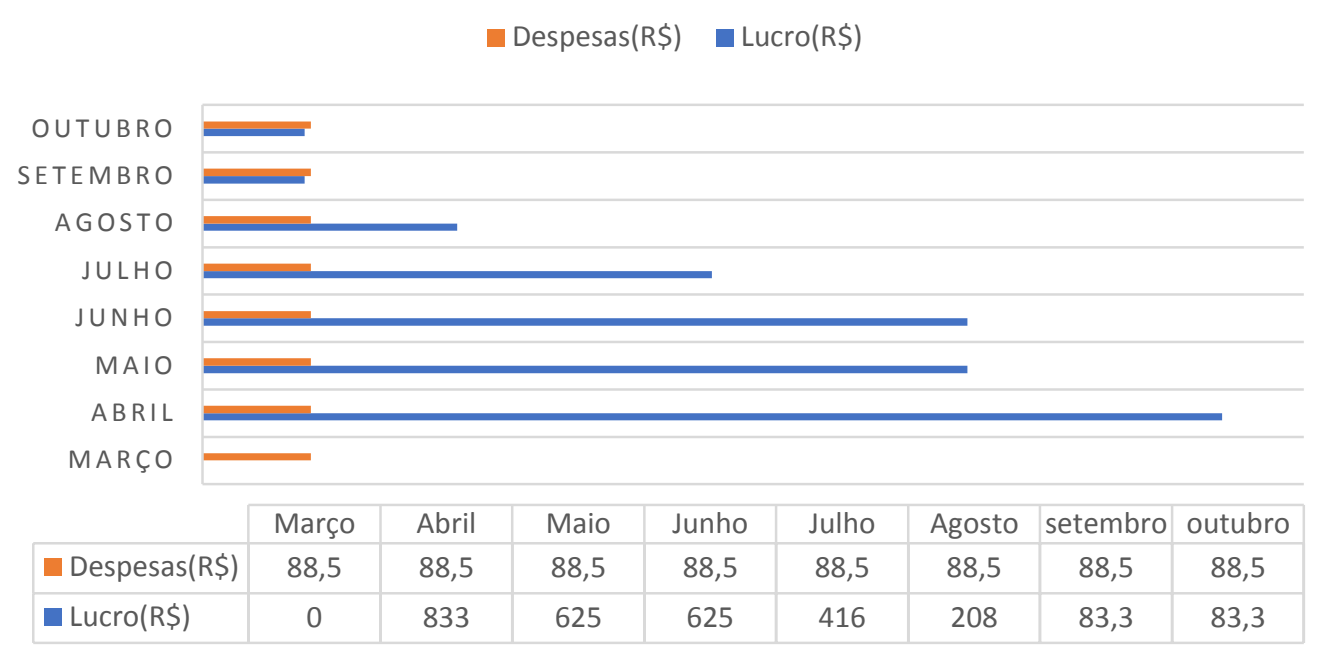

VALORES EM REAIS

Fonte: Carneiro (2018).

Analisando os dados, observa-se que os pescadores recebem menos do que um salário mínimo mensal (cerca de R\$ 998,00), para as despesas com seus familiares. Assim, apenas a atividade pesqueira não é economicamente suficiente, para a reprodução familiar dos pescadores, cujas famílias são, em geral, numerosas e constituídas por indivíduos de idades distintas, os quais vivem com o mínimo necessário à subsistência.

Assim, a pesca artesanal no rio Panacuera constitui uma atividade necessária e comum, representando uma importante fonte de renda, para a reprodução social, todavia, como já mencionado, os pescadores necessitam desenvolver outras atividades, para complementar a renda familiar, tal como o extrativismo do açaí, amplamente utilizado, como fonte de alimento e de renda.

Nesse sentido, a produção de açaí é necessária, nas comunidades pesquisadas, e, em conjunto com a pesca, é primordial, para a subsistência dos pescadores do rio Panacuera, uma vez que o açaizeiro é totalmente aproveitável, pois dele se pode obter, além de seus produtos, que são o palmito e a polpa do fruto, os subprodutos, que são as folhas, o caule, as raízes, os cachos frutíferos e as sementes. Essa palmeira é de fundamental importância, tanto para as famílias ribeirinhas como para as populações que residem na zona urbana, os quais constituem importantes consumidores do vinho do açaí.

Para Santos (2005), existem atividades complementares ao desenvolvimento da pesca artesanal em áreas de várzeas, como o extrativismo do açaí e a criação de animais de pequeno porte, utilizada como auxiliar na garantia da segurança alimentar e econômica das famílias das pequenas comunidades da Amazônia. Isso é causado pela incerteza, que assola a atividade pesqueira no estado do Pará, deixando o pescador com dupla jornada de trabalho, situação evidenciada, em várias das comunidades do rio Panacuera, em que os pescadores dividem a jornada diária de trabalho, principalmente, entre a pesca e a extração do açaí, mostrando a alta dependência financeira desses pescadores, relativamente às atividades extrativistas. 


\section{Atividades produtivas e estratégias territoriais de sobrevivência em comunidades de pescadores do Rio Panacuera (Abaetetuba - Pará - Brasil)}

No Gráfico 2, é possível evidenciar a importância da pesca artesanal, como principal atividade econômica local. Aliada a ela, outras atividades são praticadas, com a finalidade de complementar a renda familiar, as quais estão em evidência, tanto para os homens quanto para as mulheres, ou seja, muitos pescadores também realizam o extrativismo, não, somente, para alimentação, mas como atividade complementar de renda.

Gráfico 2 - Atividades econômicas desenvolvidas pelos moradores do rio Panacuera.

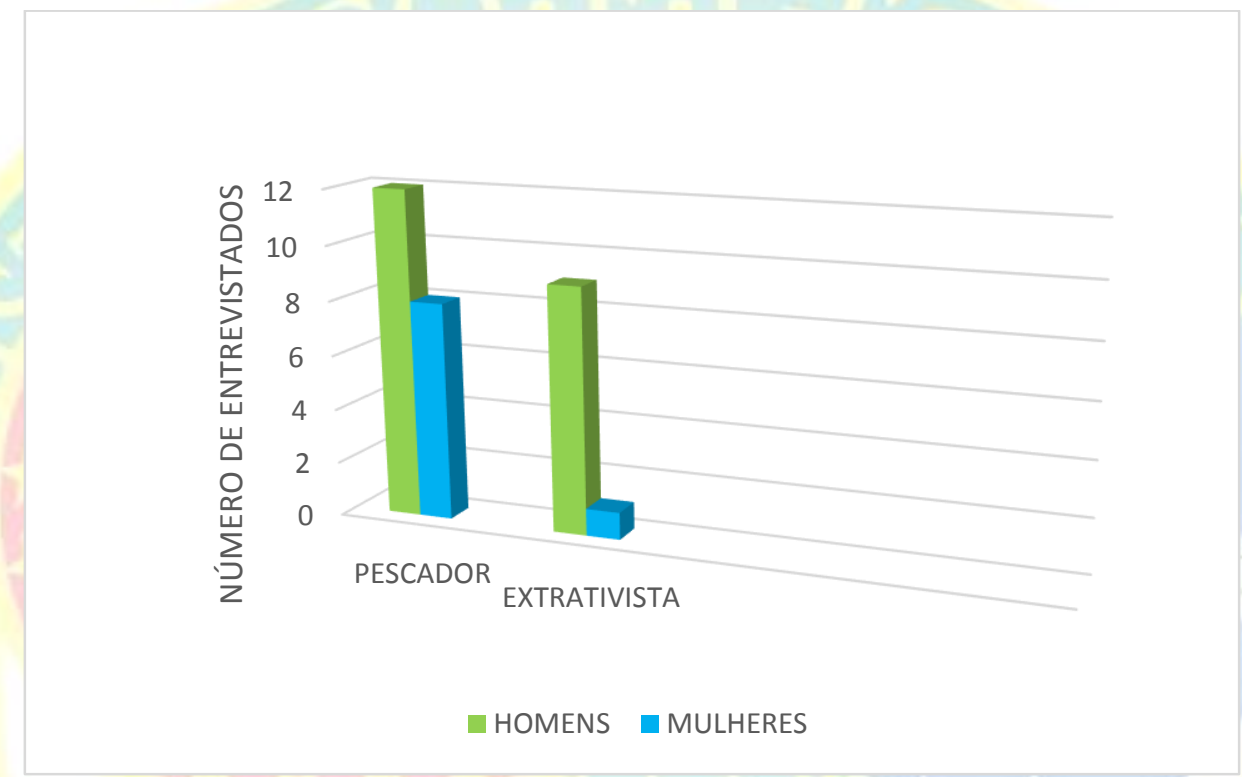

Fonte: Carneiro (2019).

Com isso, a partir da caracterização dos pescadores do rio Panacuera, pode-se identificar, entre outros aspectos, a importância do desenvolvimento de atividades paralelas, para a complementação da renda familiar das comunidades do rio estudado, pois, embora a pesca seja a principal atividade, outras contribuem, para o sustento das famílias entrevistadas, tal como o extrativismo do açaí que representa uma atividade complementar de enorme importância social na região, constituindo fonte de renda e base alimentar juntamente com o desenvolvimento da pesca artesanal na comunidade do rio Panacuera.

\section{CONSIDERAÇÕES FINAIS}

Com a compreensão adquirida, a partir das incursões a campo, das discussões de textos, das conversas com os pescadores e com os moradores locais, constatou-se que a pesca é a principal fonte de renda dessa população, mas que existem aspectos descentralizadores, que circundam a vida econômica do pescador artesanal do rio Panacuera, sendo o extrativismo do açaí, a caça e a agricultura familiar os secundários.

Como evidenciado, no decorrer do trabalho, a captura e a comercialização do pescado são fundamentais, para a sobrevivência do pescador, mas o extrativismo do açaí representa, dentre as atividades complementares, um importante suporte ao aumento da renda familiar, pois o ganho real com a atividade 
pesqueira no rio Panacuera, segundo os dados obtidos em campo, está abaixo de um salário mínimo (R \$ 998,00, no ano de 2019), devido, principalmente, à escassez do pescado, como relatado nas entrevistas.

A atividade pesqueira requer muito trabalho e necessita de habilidade, de força, de conhecimento e de agilidade, por parte do pescador, cujo amor pela profissão o impulsiona a exercê-la com maestria, em uma junção de companheirismo, de amizade e de trabalho. Todos os dias, salvo aos domingos, os pescadores se lançam aos cursos d'água na esperança de conseguir uma boa pesca. Caso não tenham êxito, eles comumente retornam no mesmo dia, para nova tentativa.

A iniciação na atividade pesqueira se dá, desde criança, com a pesca do camarão, acompanhada pelos pais e por outros familiares, para que os jovens possam ter alternativas de sobrevivência na vida adulta. Assim, todos os integrantes de uma mesma casa agregam, de alguma forma, um valor econômico e social à comunidade, seja direto ou indireto.

Portanto, a dinâmica das vidas dos pescadores do rio Panacuera faz com que eles se tornem mais companheiros e mais fraternos, uns com os outros, seja no meio familiar, seja nas atividades de pesca, buscando, sempre, alternativas para sobreviver, tendo que conciliar outras atividades à pesca, em busca de agregar valores econômicos, que possam se somar à economia familiar, culminando, muitas vezes, em uma jornada de trabalho exaustiva, situação que evidencia a relevância social e econômica da atividade do pequeno pescador artesanal e, simultaneamente, as dificuldades enfrentadas por esses sujeitos, os quais buscam se reproduzir, mantendo as condições mínimas de sobrevivência.

\section{REFERÊNCIAS}

BEGOSSI, A. Mapping spots: fishing areas or territories among islanders of the Atlantic Forest (Brazil). Reg. Environ. Change, 2001.

. Áreas, pontos de pesca, pesqueiros e territórios na pesca artesanal. In: BEGOSSI, A. (org.).

Ecologia de pescadores da Mata Atlântica e da Amazônia. São Paulo: Hucitec, 2004. p. 223-255.

. Temporal stability in fishing spots: conservation and co-management in Brazilian artisanal coastal

fisheries. Ecology and Society, v. 11, n. 5, 2006. Disponível em:

http://www.ecologyandsociety.org/vol11/iss1/art5/. Acesso em: 17 abr. 2006.

CARNEIRO. J. D. S. Viabilidade Econômica da Pesca: Identificação da Reprodução Social de Pescadores do rio Panacuera, no município de Abaetetuba/PA. (Dissertação de Mestrado). Programa de Pós-Graduação em Gestão de Recursos Naturais e Desenvolvimento Local na Amazônia - PPGEDAM

DIEGUES, A. C. Povos e águas. São Paulo: NUPAUB-USP, 2012.

O mundo social dos pescadores artesanais brasileiros. São Paulo: CEMAR-USP, 1993. (Série

Documentos e Relatórios de Pesquisa, $\mathrm{n}^{\circ}$ 8)

Tradição e mudança: diversas formas de produção na pesca. São Paulo: NUPAUB-USP, 2012.

FERRI, L. A ilha Monte de trigo: impressões de viagens. In: DIEGUES, A. (Org.). Ilhas e sociedades

insulares. São Paulo: NUPAUB-USP, 1997. p. 137-153. 
FURTADO, L. G. Pescadores do Rio Amazonas: um estudo antropológico da pesca ribeirinha numa área amazônica. BELEM: CNPQ/MPEG, 1993. 486 p.

MORAES, S. C. et al. Delineamento da situação das organizações sociais de pescadores amazônicos: o caso do Nordeste Paraense. In: XIMENES, T. (Org.). Políticas pesqueiras nos países amazônicos. Belém: UNAMAZ/NAEA/UFPA, 1996. p. 437-502.

MORAES, S. C. et al. Uma arqueologia dos saberes da pesca: Amazônia e Nordeste. Belém: EDUFPA, 2007.

SANTOS, M. A. S. A cadeia produtiva da pesca artesanal no estado do Pará: estudo de caso no nordeste paraense. Amazônia: Ciência \& Desenvolvimento, Belém, v. 1, n. 1, p. 61-81, jul. dez. 2005.

SAPOPEMA. Sustentabilidade da Pesca e manejo integrado dos recursos naturais do Baixo Amazonas.

Disponível em: http://www.sapopema.org/pesca-artesanal. Acesso em: 15 fev. 2021

SILVA, C. N. Territorialidade e modo de vida de pescadores do rio Ituquara, Breves-PA. Dissertação

(Mestrado e Geografia) - Universidade Federal do Pará, Instituto de Filosofia e Ciências Humanas, Belém, 2006.SILVA, C. N.; VILHENA, T. M.; SILVA, J. M. P.; LIMA, R. A. P.; SOUSA, H. P.; BARRA, J.

Territorialidades e estratégias de sobrevivência de populações amazônidas no rio Acaraqui (AbaetetubaAmazônia-Brasil). Interespaço: Revista de Geografia e Interdisciplinaridade, v. 4, p. 08-31, 2018.

SILVA, C. N.; SOUSA, H. P.; VILHENA, T. M.; BARRA, J.; SILVA, J. M. P. Modo de vida e territorialidades de pescadores da comunidade Cajueiro em Mosqueiro (Belém-Amazônia-Brasil). Revista NERA (UNESP), v. 20, p. 246-272, 2017.

SILVA, C. N.; LIMA, R. S.; SILVA, J. M. P.; LIMA, R. A. P.; VILHENA, T. M.; MONTEIRO, P. G. B. Estratégias de sobrevivência na Amazônia Paraense: o caso dos moradores do baixo Rio Meruú (IgarapéMiri/Pará/Brasil). Geosul, v. 31, p. 151-172, 2016. 